\title{
Temos de fazer um cavalo de Troia elementos para compreender a internacionalização da investigação e do ensino superior*
}

\author{
EMÍLIA RODRIGUES ARAÚJO \\ Universidade do Minho, Braga, Portugal \\ SÍLVIA SILVA \\ Universidade do Minho, Braga, Portugal
}

\section{RESUMO}

O texto tem como objectivo discutir a diversidade de sentidos atribuídos à internacionalização na investigação e no ensino superior. A internacionalização tem sido objecto de inúmeras referências no âmbito das políticas de avaliação da qualidade do ensino e da investigação. Ao mesmo tempo, tem gerado várias interpretações tanto em seu favor como em seu desfavor. Procuramos perceber quais são as razões para que os atores organizacionais com mais poder de intervenção política veiculem uma representação extremamente positiva da internacionalização, apesar de nem sempre identificarem os indicadores e as formas que a medição desse processo deve comportar. A pesquisa tem um carácter exploratório e debruça-se de modo especial sobre dados recolhidos por meio da observação participante e de uma série de entrevistas realizadas por correio electrónico a reitores, vice-reitores e directores de centro de investigação portugueses.

\section{PALAVRAS-CHAVE}

internacionalização; mobilidade; investigação.

* Este texto é uma versão extensa das comunicações apresentadas pelas autoras no Colóquio Internacional CRASSH Workshop on Internationalisation in Higher Education: Socio-legal Perspectives on Contemporary Mobilities, organizado no Wolfson College, em Cambridge, entre 17 e 18 de novembro de 2012. Insere-se no projecto MobScience (PTDC/ESC/64411/2006), financiado pela Fundação para a Ciência e a Tecnologia (FCT), do qual integra na equipa Margarida Fontes, Pedro Videira, Luísa Henriques e Sofia Bento. O texto integra dados já tratados no âmbito de uma dissertação de mestrado (Silva, 2011). 
WE HAVE TO MAKE A TROJAN HORSE: ELEMENTS

TO UNDERSTAND INTERNATIONALIZATION IN

THE HIGHER EDUCATION AND RESEARCH

\section{ABSTRACT}

The text aims to discuss the diversity of meanings attributed to the term internationalization in research and higher education. Internationalization has been the subject of numerous references in the policies for evaluating the quality of teaching and research. At the same time, it has generated various interpretations both in its favor, and to its disadvantage. We seek to understand why organizational actors, with more political power for intervention, convey an extremely positive representation of internationalization, although not always identifying the indicators and the correct ways of measurement for this process. The research has an exploratory nature and focuses in particular on data collected through participant observation and several interviews conducted via e-mail to university deans, vice deans and directors of Portuguese research centers.

\section{KEYWORDS}

internationalization; mobility; research.

\section{TENEMOS QUE HACER UN CABALLO DE TROYA: ELEMENTOS PARA ENTENDER LA INTERNACIONALIZACIÓN EN LA EDUCACIÓN SUPERIOR E INVESTIGACIÓN}

\section{RESUMEN}

El texto tiene como objetivo discutir la diversidad de significados que se atribuyen a la internacionalización de la investigación y a la educación superior. La internacionalización ha sido objeto de numerosas referencias en las políticas de evaluación de la calidad de la enseñanza y de la investigación. Al mismo tiempo, ha generado diversas interpretaciones, tanto en su favor, como en su contra. Tratamos de entender cuáles son las razones por las que los actores de las organizaciones con más poder de intervención política transmiten una representación muy positiva de la internacionalización, aunque no siempre identificando los indicadores y las formas en que la medición de este proceso deba realizarse. La investigación tiene un carácter exploratorio y se centra, en particular, en los datos recogidos a través de la observación participante y una serie de entrevistas llevadas a cabo por correo electrónico a los rectores, los vicerrectores y directores de centros de investigación portugueses.

PALABRAS CLAVE

internacionalización; movilidad; investigación. 


\section{INTRODUÇÃO}

A internacionalização define-se como um processo "de integração de uma dimensão internacional e intercultural no ensino, na investigação e nas tarefas administrativas de uma instituição" (Knight, 1994 apud Knight, 1999, p. 16). Nesse sentido, uma das ideias fortes que percorre a literatura sobre a globalização e a internacionalização do conhecimento propõe que, no quadro do decréscimo demográfico e da acentuada mercadorização de todos os processos relacionados com a produção científica, as nações necessitam criar espaços de visibilidade no mundo global, como forma de manter sua legitimidade e reforçar sua singularidade. Mas as questões que se levantam à satisfação dessa necessidade são várias e complexas. Tal complexidade explica-se, em primeiro lugar, pela diversidade de princípios políticos que orientam (e podem orientar) as estratégias de internacionalização. Nesse ponto, é necessário avaliar três elementos principais:

a) O lugar do conhecimento na economia global e os modelos de relacionamento social e económico entre países;

b) As lógicas e as regras a serem seguidas pelos atores individuais (investigadores) e coletivos no desenvolvimento dos seus desempenhos diante da qualidade das políticas públicas nesse campo; e

c) A definição dos modelos de qualidade de excelência que se apresentam como referenciais, conforme as áreas científicas e as características das estratégias de liderança organizacional adaptadas à gestão do conhecimento em ambientes instáveis.

O propósito deste texto consiste em clarificar os sentidos atribuídos à internacionalização da investigação e do ensino superior pelos atores que detêm poder de decisão e intervenção sobre as práticas organizacionais nas universidades e nos centros de investigação em Portugal, nomeadamente reitores, vice-reitores e diretores de centros de investigação. Confere-se especial atenção ao modo como definem a internacionalização, perspetivam sua avaliação, no quadro das especificidades das diferentes áreas científicas, e lhe reconhecem ou não importância.

Nessa linha, o texto tem um carácter introdutório relativamente à temática da internacionalização, assumindo-se como exploratório no que concerne aos dados recolhidos e analisados no contexto dos sistemas de ensino superior e investigação em Portugal. A argumentação que seguimos assenta em três pressupostos centrais:

a) Assiste-se crescentemente nos contextos quotidianos a uma enfase acentuada acerca da necessidade de ações no sentido da internacionalização da área da ciência da investigação e do ensino superior (Araújo; Silva, 2010);

b) Os atores organizacionais com mais responsabilidades na realização de programas e políticas demonstram um nível de concordância elevado com a necessidade de incluir a internacionalização como dimensão central da práxis organizacional, assim como da práxis avaliativa do trabalho dos docentes, investigadores e centros de investigação; e 
c) Todos esses saberes e certezas sobre as vantagens da internacionalização parecem surgir num contexto em que os mesmos atores não são capazes de identificar nem os indicadores da internacionalização nem as modalidades da internacionalização que mais se adaptam às diferentes áreas disciplinares.

$\mathrm{O}$ texto divide-se em quatro pontos fundamentais. $\mathrm{O}$ primeiro desenvolve o conceito de internacionalização, propondo a fundamentação das hipóteses que atravessam este estudo. $\mathrm{O}$ segundo ponto versa sobre a metodologia. $\mathrm{O}$ terceiro é dedicado a análise da informação recolhida, percorrendo as dimensões inscritas nas perguntas apresentadas anteriormente, designadamente a definição de internacionalização, a influência desta sobre as carreiras e a notoriedade dos centros e das universidades e sua valorização nas diferentes áreas científicas. No quarto ponto apresentamos as principais conclusões do estudo, avançando algumas das recomendações mais pertinentes, do ponto de vista das políticas.

\section{INTERNACIONALIZAÇÃO EM CIÊNCIA E NO ENSINO SUPERIOR}

\section{CONTEXTOS E (NOVAS) GEOGRAFIAS}

A internacionalização da investigação e do ensino superior pode ser considerada um processo com longa trajectória histórica, cujo início é inerente ao próprio desenvolvimento do conhecimento (Knight, 1999, 2004, 2006; Knight; De Wit, 1995; Siegler, 2009). Há autores que localizam a emergência desse processo no século XIII (Miura, 2006; Morosini, 2006; Siegler, 2009). Apesar de tudo, ele afirma-se no período pós-iluminista, caracterizado pelo domínio do paradigma positivista e racionalista dos séculos XVIII e XIX (Amaral et al., 2013; Silva, 2011; Veiga, 2012). Tem seu auge nos pós anos 1970, com as vastas transformações nos modos de vida e na reconfiguração dos setores produtivos provocadas pelos avanços tecnológicos. Hoje ele surge percepcionado como um dos elementos fundamentais para a reprodução e o incremento dos sistemas nacionais de ciência e tecnologia e, inclusive, dos sistemas de ensino superior (primeiro, segundo e terceiro ciclo).

Albino (2008, p. 116) identifica cinco fatores na explicação do interesse pela internacionalização:

i) A crescente dependência dos Estados-nação em uma sociedade da informação e do conhecimento e a consequente criação de redes de cooperação;

ii) A mundialização da ciência e a formação de projectos globais que surgem, em boa parte, da criação de organizações multilaterais e da associação de países em projetos conjuntos; ${ }^{1}$

1 Como exemplo, o projecto científico desenvolvido pelo European Organization for Nuclear Research (CERN) (Albino, 2008, p. 116). 
iii) A mobilidade de recursos humanos da ciência e tecnologia (investigadores, professores e estudantes), resultado de programas bilaterais e multilaterais de intercâmbio, que, por sua vez, são decorrentes das políticas de desenvolvimento, no espaço europeu e na esfera mundial;

iv) $\mathrm{O}$ advento de um conceito de mercado na educação superior e na investigação, que levou à formação de nichos de mercado em torno da produção científica; e, finalmente,

v) A avaliação externa das universidades a partir da qual se produzem rankings que as posicionam no sistema-mundial da ciência.

Miura (2006, p. 30) define a internacionalização com um esforço sistemático e sustentado no intuito de conduzir o ensino superior a responder às exigências e aos desafios da globalização manifestos na organização económica e no mercado de trabalho das sociedades de conhecimento. Segundo a mesma autora, existem diversas razões que podem explicar as tendências hoje observadas, no sentido da internacionalização do ensino superior e da investigação. Entre estas estão: i) a busca de paz e entendimento; ii) a procura de competitividade, interculturalidade e diálogo; iii) a promoção da qualificação adequada para um mercado de trabalho global; e iv) a consolidação da reputação das instituições de ensino superior.

Serge e Wise (2010, p. 7 et seq.) consideram que a internacionalização comporta três dimensões principais: i) a exploração de mercados internacionais para ideias e produtos desenvolvidos num país; ii) o desenvolvimento de produtos e ideias em um nível global e transnacional; e iii) as colaborações internacionais e transnacionais entre centros de investigação, empresas de Investigação e Desenvolvimento (I\&D) e universidade. $\mathrm{Na}$ linha de pensamento desses dois autores, a internacionalização é movida por uma série de fatores, entre os quais está a mudança na geografia dos processos de transferência e de inovação do conhecimento, a qual obriga à concentração da atenção dos esforços das instituições e dos países em lugares que progressivamente se destacam na liderança dos processos de investigação e inovação.

Na perspectiva desses autores (idem, p. 8), aliás, a internacionalização concentra hoje a atenção sobre a China, o Brasil e a Índia, países que, em sua análise, são:

talvez os exemplos mais proeminentes de países onde os investimentos nacionais em $\mathrm{P} \& \mathrm{D}$ e o número de estudantes, engenheiros e pesquisadores estão crescendo dramaticamente, ao mesmo tempo que os seus mercados domésticos estão atraindo investimentos de $\mathrm{P} \& \mathrm{D}$ de empresas estrangeiras.

Serge e Wise especificam que a internacionalização é um processo estrutural que respeita primeiramente o nível da política, por meio da qual a ação dos atores, sobretudo investigadores, é constrangida, podendo comportar um leque de desvantagens para alguns países. Os autores afirmam que:

como as empresas estão a criar cada vez mais centros de pesquisa fora dos seus países de origem (ver, por exemplo, Karlsson, 2006), e como um conjunto crescente de capital humano altamente especializado acaba trabalhando em outros 
países que não aqueles onde foram educados, torna-se cada vez mais difícil para os governos nacionais assegurar que os retornos sobre os investimentos em pesquisa e educação sejam aplicados e usados nos países de origem. Mais especificamente, a pesquisa científica pode ser cada vez mais realizada em (e financiado por) um país, mas gerar benefícios económicos ou comerciais no outro país. (idem, p. 9)

Acontece que, não obstante a internacionalização poder definir um processo de troca e de intercâmbio em nível internacional, com vantagens para os países envolvidos, surge evidente o risco de perda progressiva de capital humano e, subsequentemente, de capital científico e de capacidade de inovação para alguns países, isto é, aqueles que apresentem características de maior fragilidade ao nível da posse de meios objetivos de experimentação do conhecimento e de capacidade de inovação.

Com efeito, a ciência foi tradicionalmente representada como um "bem" universal por vários autores, incluindo Stoer (1970, p. 118), que escrevia em 1970:

Se os fenómenos físicos básicos são universais e o progresso da ciência deve seguir geralmente um único caminho, conclui-se que a localização do cientista no espaço (senão no tempo) é irrelevante para suas oportunidades de ajudar neste progresso - contando que tenha acesso adequado à informação sobre o estado actual de sua especialidade e o equipamento necessário para empenhar-se em pesquisa neste campo.

Mas, ainda que possamos aceitar a ciência como global (Castells, 1999), as nações são especificamente visadas nos processos de avaliação da ciência e tecnologia: a produção científica conta a favor do país que detém o controlo sobre os espaços e os meios de produção da ciência, o que torna o lugar um fator deveras "relevante". No fundo, a internacionalização continua a pôr questões de fundo no que respeita à posse e à propriedade da ciência.

Fortuna havia proposto em 2008 uma interpretação muito completa do dilema emergente do conflito entre a importância cada vez menor dos locais e das fronteiras para a produção e a circulação do conhecimento e a persistência do valor económico, político e simbólico do lugar de produção de conhecimento e inovação. Com efeito, afirma esse autor que, se "a ciência é virtude universal" (Fortuna, 2008, p. 84), fonte de desenvolvimento econômico-social dos países, sua definição geopolítica faz-se de acordo com processos de hegemonização e racionalização predominantes na economia capitalista e que têm por base a divisão do trabalho e as relações de produção internacionais assentes em uma lógica de dominação que une os interesses das classes dominantes dos países centrais contra os interesses das classes dominadas dos países periféricos. Essa ideia surge também vincada por Nunes e Gonçalves (2001), que relacionam a internacionalização com a crescente fragilização dos estados nação e o surgimento de formas de governo supranacionais, não vincadamente integradoras de todas as diferenças interpaíses. Os autores afirmam o seguinte: 
A emergência de entidades supranacionais como a União Europeia veio conferir uma acrescida visibilidade às modalidades de internacionalização e de articulação entre as escalas local, nacional e transnacional nesse domínio, e criar para elas um quadro institucional que tornou possível uma relativa estabilização de alguma dessas articulações. É na intersecção entre estas duas ordens de relações - entre mundos sociais e entre escalas - que se define a condição central, periférica ou semiperiférica do contexto em que se "faz ciência". (idem, p. 15)

Interessa destacar, pois, do quadro analítico apresentado pelos diversos autores citados, a tese de que a internacionalização é fruto da globalização e, por isso, torna-se, acima de tudo, uma forma específica de fazer política em nível nacional e internacional. Importa ainda destacar que a internacionalização ao nível da investigação revela-se, designadamente, pela constante eleição de áreas do saber e de temas de investigação nos quais se concentram os esforços humanos e materiais nacionais, no sentido de gerar capacidade de sobressair no exterior, pela demonstração de exclusividade e de trabalho original. Essa postura exige uma política de administração da ciência algo dirigista, na medida em que se seleccionam áreas prioritárias e modos de atuação no exterior, sendo evidentemente seleccionados também os parceiros de colaboração. Os investigadores ficam bastante confinados a processos de trabalho pré-determinados. No nível do ensino superior, a internacionalização abarca uma série de dimensões. Mas, entre essas, destaca-se a mobilidade de estudantes e de professores, o que supõe mecanismos de equivalências e de reconhecimentos complexos.

\section{MEDIR INTERNACIONALIZAÇÃO E ESCALAS DE ANÁLISE}

Tal como detalha Miura (2006, p. 30), Arum e Van de Water “consideravam a internacionalização como um processo constituído de múltiplas actividades, programas e serviços relacionados com os estudos internacionais, cooperação técnica e intercâmbios educacionais internacionais”. Alguns anos depois, Soderqvist (2002) afirmava que aquele processo correspondia à inclusão da "dimensão internacional em todos os aspectos da sua administração visando melhorar a qualidade do ensino e aprendizagem e alcançar as competências desejadas" (apud Miura, 2006, p. 30). Assim definida, a internacionalização expressa-se em algo mais do que a participação momentânea em atividades internacionais Ela atinge triplamente a investigação, o ensino e a inovação (e processos de transferência do conhecimento). Pereira (2001, p. 145) afirma que:

a internacionalização faz parte integrante do trabalho científico produzido, com investigadores de diferentes países em contacto mais frequente, e não apenas por ocasião de encontros ocasionais.

Segundo Green (2005), a internacionalização pode comportar seis dimensões: i) o compromisso articulado entre instituições e atores; ii) as ofertas acadêmicas; iii) a infraestrutura organizacional; iv) o financiamento externo; v) o investimento institucional na faculdade; e vi) os estudantes internacionais e programas estudantis. 
A autora diferencia as universidades "passivas" das universidades "ativas", relativamente às políticas de internacionalização, chamando a atenção para o fato de as universidades mais ativas revelarem um intenso trabalho, investimento humano, financeiro e político na promoção da internacionalização, que não comporta apenas a definição de colaborações de programas e protocolos de cooperação, mas também a construção de processos de equivalência automática de graus e programas de ensino iguais ou semelhantes nas instituições situadas em países distintos. A aprendizagem de um língua estrangeira e a existência de cursos nessa língua, assim como o apoio efetivo logístico e institucional à publicação e à realização de projetos em cooperação, constituem três vértices apontados pelos autores como fundamentais para a existência da internacionalização.

Algumas análises centram-se na dimensão institucional da internacionalização, propondo um foco orientado para a ação política do Estado e dos agentes políticos na realização de medidas e programas de intercâmbio e de dinamização da colaboração internacional.

Há autores que enfatizam a ação dos atores individualmente considerados, entre os quais os investigadores e professores do ensino superior. Mas outros autores têm vindo a demonstrar as vantagens e a necessidade de pontos de vista mais integradores entre os níveis institucionais e macroestruturais e os níveis da ação individual. Knight $(1999,2004)$ considera ser importante perceber que o nível da ação nacional, isto é, das políticas e da definição de programas e estruturas financiadoras, é extremamente importante e constrangedor da ação das instituições e dos atores. Mas o olhar da autora centra-se justamente na dimensão institucional, isto é, na forma como as universidades e os centros de investigação individualmente considerados podem fazer a diferença, construindo modelos e esquemas de internacionalização adaptados aos processos concretos e às culturas organizacionais específicas.

$\mathrm{Na}$ perspectiva dessa autora, sem a ação institucional não há forma nem de operacionalizar os programas e as políticas nacionais nem de integrar a ação e o voluntarismo individual. Essa perspetiva é também partilhada por Antelo (2012, p.3), que considera relevante levar em conta em um processo de internacionalização de investigação as questões políticas, culturais e de segurança e estabilidade políticas.

\section{DIÁLOGOS E DISTINÇÕES}

Os campos científicos são campos de poder e de luta permanente por recursos materiais e simbólicos. Os processos de legitimação dos saberes e de imposição do valor das áreas científicas são contínuos e envolvem um empenho constante da parte dos atores que tentam impor sistemas de classificação e de valorização (Bourdieu, 1984).

Há diferenças entre as culturas científicas na forma como se organizam os processos de produção e disseminação do conhecimento (Jons, 2007). Tal como argumenta essa autora, as assimetrias que se verificam entre as diferentes áreas científicas são resultado de variações nas políticas, no desenvolvimento socioeconómico, nas relações culturais e históricas na tradição de investigação, prioridades políticas e modelos de estandardização de prestígio, assim como nas diferentes culturas de mobilidade e de colaboração inter disciplinas (idem, p. 102). 
Nessa linha, a internacionalização, como processo de recȩ̧ão do exterior, ou de ganho de presença no exterior, implica um posicionamento político sobre o estatuto, a situação e o caminho das diferentes áreas do saber, atendendo às suas dinâmicas culturais, fundamentos e finalidades.

Hakala (1998) explicita que a internacionalização tem significados distintos nas diferentes culturas disciplinares: há diferenças entre as ditas ciências "duras" e as ciências "moles". Segundo a autora, um maior impacto internacional em ciências exatas pode ser explicado, por exemplo, em termos da natureza universal dos próprios temas de investigação, bem como pela tradição disciplinar de publicar quase que exclusivamente em revistas internacionais (idem, p. 54).

Algumas disciplinas podem ser, igualmente, mais resistentes à mudança, enquanto outras podem ser mais facilmente receptivas ao desenvolvimento da ciência, à interacção entre académicos ou mesmo às pressões vindas da sociedade. Jons (2007) afirma, por exemplo, que as práticas científicas variam em seus graus de materialidade e imaterialidade. Depois, é importante notar que diferentes áreas podem ter contatos e colaboração em diferentes direções, e certos países podem ter mais contatos com alguns países e menos com outros (idem, ibidem). Tais diferenças podem ser explicadas por factores endógenos ou exógenos, ligados a evoluções históricas, económicas e geopolíticas (idem, ibidem) diferenciadas. Afinal, tal como nos diz Pereira (2001, p. 166):

a heterogeneidade da ciência significa que o conhecimento científico não pode ser considerado como informação facilmente transmissível. O seu conteúdo tácito e material requer a sua ligação a uma série de outros elementos, técnicas e práticas, que garantem o alinhamento entre diferentes locais. As colaborações internacionais proporcionam, e evidenciam, modos de articulação entre o local e o global e o acesso a uma diversidade existente para além das fronteiras do laboratório e dos sistemas nacionais de investigação.

\section{PERFORMATIVIDADE}

As organizações são produtoras de cultura e constroem-se sob dinâmicas complexas de sentido e de significado, podendo oferecer-se como espaços de apropriação e de construção simbólica. A internacionalização, enquanto palavra-chave do paradigma managerial moderno, é permeável e oferece-se a esses processos de construção, por meio dos quais produz efeitos reais nos universos quotidianos da acão organizacional. E, enquanto palavra e ato de linguagem, nomeia, corporiza e consubstancia uma realidade, adquirindo um estatuto performativo, no sentido em que "faz uma realidade": ela assume protagonismo como se existisse "de fato".

Hakala (1998) incide sobre o caráter performativo que pode ter a internacionalização e seus efeitos perversos ao lembrar que, por vezes, ela é entendida como sinónimo de qualidade e excelência, quando, na realidade, estamos (deveremos estar) a falar de coisas muito distintas e não necessariamente ligadas de forma causal.

A internacionalização ganha essa vertente ilusória e quase alquímica a partir do momento em que deixa de ser entendida como um meio e passa a valer como um 
fim em si mesmo, autodesignando um conjunto de atributos susceptíveis de serem classificados como necessariamente vantajosos e imprescindíveis nos processos de construção identitária das universidades e centros de investigação, que incluem a determinação dos países com os quais se deve colaborar.

Hakala (idem) observa ainda que esse carácter performativo da internacionalização pode conduzir os atores organizacionais e os responsáveis políticos a responderem mais aos interesses de certas organizações e países do que às necessidades das comunidades e dos países envolventes das instituições. Nesse sentido, a sede de internacionalização também pode configurar um certo tipo de "imperialismo científico" (Alatas, 2005) regulado pelos países que concentram as instituições científicas com monopólio sobre os meios de orientações no domínio da ciência e que podem ditar as regras pelas quais (supostamente) se faz ciência, incluindo a definição dos objetos de estudo, as escolhas metodológicas e os modos de disseminação.

\section{METODOLOGIA}

A maior parte dos estudos consultados sobre a temática da internacionalização ou são marcadamente reflexivos ou baseiam-se em dados obtidos por meio de inquérito por questionário. $\mathrm{O}$ estudo que conduzimos pautou-se por uma extensa pesquisa bibliográfica, a partir da qual se efectuaram entrevistas estruturadas a reitores, vice-reitores e directores de centro de investigação em Portugal. A população alvo do estudo - equipas reitorais e directores de centro - apresenta algumas características particulares, por ser uma população de difícil acesso, que procura salvaguardar o ponto de vista institucional, não estando, à partida, muito disposta a ser foco de análise.

Por se tratar ainda de uma temática que em Portugal tem merecido pouca atenção por parte da sociologia, e atendendo a essas dificuldades, optou-se por realizar entrevistas estruturadas e directivas, dirigindo o pedido de resposta a todas as equipeas reitorais das universidades públicas portuguesas, em um total de catorze. Em um segundo momento, o mesmo pedido foi enviado a todos os coordenadores científicos, perfazendo um total de 407 unidades de I\&D.

As entrevistas foram pedidas pessoalmente, mas a falta de disponibilidade demostrada conduziu à sua realização mediante a internet, tendo sido enviadas as questões por meio de correio electrónico e obtidas as respostas usando o mesmo meio. Do total de envios, foram obtidas respostas de 23 contatos, tal como se encontra no Quadro 1.

Importa ainda acrescentar que os guiões de entrevista foram estruturados de modo que reduzisse a dispersão dos entrevistados, visando exclusivamente os pontos de interesse na investigação. Assim, as questões colocadas foram as seguintes:

a) Hoje, afirma-se que a internacionalização constitui um dos grandes cami nhos para o desenvolvimento do ensino superior e da investigação em Portugal. Gostariamos de saber como define a internacionalização; 
Quadro 1 - Breve caracterização dos respondentes

\begin{tabular}{|clc|}
\hline Número & \multicolumn{1}{|c|}{ Cargo } & Sexo \\
\hline \multicolumn{1}{|c|}{ Reitores, vice-reitores e pró-reitores } \\
\hline 1 & Vice-reitor & $\mathrm{M}$ \\
2 & Vice-reitor & $\mathrm{F}$ \\
3 & Vice-reitor & $\mathrm{F}$ \\
4 & Pró-reitor & $\mathrm{M}$ \\
5 & Vice-reitor & $\mathrm{M}$ \\
6 & Vice-reitor & $\mathrm{M}$ \\
7 & Reitor & $\mathrm{M}$ \\
8 & Pró-reitor & $\mathrm{F}$ \\
9 & Vice-reitor & $\mathrm{M}$ \\
\hline Número & & $\mathrm{Sexo}$ \\
\hline & & \\
\hline 10 & \multicolumn{1}{c|}{ Carrectores de Centro de Investigação } & $\mathrm{F}$ \\
11 & Ciências da saúde & $\mathrm{M}$ \\
12 & Ciências exactas & $\mathrm{M}$ \\
13 & Ciências da engenharia e tecnologia & $\mathrm{M}$ \\
14 & Ciências da saúde & $\mathrm{M}$ \\
15 & Ciências exactas & $\mathrm{M}$ \\
16 & Ciências da engenharia e tecnologia & $\mathrm{M}$ \\
17 & Ciências da saúde & $\mathrm{M}$ \\
18 & Ciências da engenharia e tecnologia & $\mathrm{M}$ \\
19 & Artes e humanidades & $\mathrm{F}$ \\
20 & Ciências naturais & $\mathrm{M}$ \\
21 & Ciências sociais & $\mathrm{F}$ \\
22 & Ciências sociais & $\mathrm{M}$ \\
23 & Artes e humanidades & $\mathrm{F}$ \\
\hline
\end{tabular}

Fonte: Inquéritos por questionário $(\mathrm{N}=23)$.

Elaboração das autoras.

b) É frequente assumir-se que "quanto mais internacional for uma instituição ou uma carreira, melhor". Concorda com esta afirmação? Pode dizer-nos por quê??

c) $\mathrm{Na}$ sua opinião, qual é a melhor forma de promover a internacionalização (na investigação; e no ensino); e

d) Em Portugal, a avaliação do nível de internacionalização tem vindo a ser realizada usando o mesmo tipo de metodologia, em todas as áreas científicas. Concorda com esse modo de proceder? Por quê??

Por fim, efectuou-se uma análise de conteúdo de entrevistas realizadas no âmbito do projecto MobScience $(\mathrm{N}=18)$ a atores ocupando cargos de directores de centro de investigação, tal como se encontra descrito no quadro que apresentamos no Quadro 2. 
Quadro 2 - Centros de investigação onde se realizaram as entrevistas

\begin{tabular}{|clll|}
\hline Número & Área científica & Dimensão Centro & Classificação FCT* \\
\hline 1 & Ciências da saúde & Médio & N/D \\
2 & Ciências da engenharia e tecnologia & Pequeno & Positiva \\
3 & Ciências da engenharia e tecnologia & Médio & N/D \\
4 & Ciências da engenharia e tecnologia & Pequeno & Muito Positiva \\
5 & Ciências da engenharia e tecnologia & Médio & N/D \\
6 & Ciências da engenharia e tecnologia & Grande & Positiva \\
7 & Ciências sociais & Grande & Muito Positiva \\
8 & Ciências sociais & Médio & Muito Positiva \\
9 & Ciências da engenharia e tecnologia & Médio & N/D \\
10 & Ciências sociais & Grande & Muito Positiva \\
11 & Ciências da saúde & Grande & Muito Positiva \\
12 & Ciências da saúde & Médio & Muito Positiva \\
13 & Ciências sociais & Médio & Positiva \\
14 & Ciências da engenharia e tecnologia & Grande & Positiva \\
15 & Ciências sociais & Pequeno & Negativa \\
16 & Ciências da engenharia e tecnologia & Pequeno & Negativa \\
17 & Ciências sociais & Médio & Muito Positiva \\
18 & Ciências sociais & Pequeno & Negativa \\
\hline
\end{tabular}

Fonte: Entrevistas realizadas no projeto MobScience $(\mathrm{N}=18)$.

*FCT: Fundação para a Ciência e a Tecnologia.

Elaboração das autoras.

Foi possível obter respostas de diversas universidades, com história e posicionamentos geocientíficos distintos, assim como respostas de personalidades atualmente no Ministério de Ciência e Tecnologia. Os dados sugerem uma elevada consistência. A informação recolhida por meio de entrevista e dos restantes meios foi tratada com recurso a análise de conteúdo. Nessa análise tiveram-se em conta as dimensões de análise já evocadas: a definição da internacionalização e sua importância; a identificação de seus indicadores de avaliação e as orientações de política veiculadas ou sugeridas pelos atores.

\section{A INTERNACIONALIZAÇÃO NA ÓTICA DOS ATORES: ENTRE O CAVALO DE TROIA E A GESTÃO DE MOBILIDADE}

A frase "temos de fazer um cavalo de Troia" que aparece citada no título foi proferida no decurso de uma das apresentações sobre a internacionalização. ${ }^{2}$ Para esse investigador e diretor de centro de investigação com doutoramento e outras formações realizadas nos Estados Unidos da América, a solução para as

2 Conferimos a esse dado o estatuto de informação recolhida por meio de observação, pois a frase foi recolhida no contexto de um evento científico no qual as autoras do presente texto participaram. 
universidades portuguesas, tradicionalmente sujeitas ao poder dos países centrais na Europa e no mundo, traduz-se na adoção "estratégica" de duas medidas de política.

Por um lado, a organização de lobbying científico estruturado nos centros de decisão supranacionais com influência sobre as políticas nacionais e orientado para a abertura de canais de relacionamento entre organizações e centros de desenvolvimento tecnológico e científico mundiais. Por outro lado, a condução de estratégias de internacionalização tipo "cavalo de Troia”, caracterizadas pela criação de infraestruturas, como centros de investigação, universidades e empresas nas cidades e países atualmente polos de concentração de pesquisa e desenvolvimento, entre os quais os Estados Unidos (Boston e Harvard) e, designadamente, os países que demonstram ter algum potencial para o desenvolvimento de projetos nacionais, como os países de língua oficial portuguesa e países emergentes, para onde se crê ser possível "expandir" as instituições de ensino.

Outro investigador, também diretor de centro multidisciplinar e vice-reitor de uma universidade pública, ${ }^{3}$ afirmava, no mesmo sentido, ser-lhes vital "conquistar" alunos dos países da Europa do leste e do Brasil para os programas de doutoramento e pós-doutoramento. Assinalava esse director de centro que, por meio desses contatos, conseguiam chegar a polos mundialmente reconhecidos, como Boston ou Harvard. Para isso, relata como e por que deslocam todos os anos comitivas de representantes para visitas a universidades no Brasil e em outros países de língua oficial portuguesa.

No que concerne às entrevistas realizadas, a maioria dos entrevistados concorda com a afirmação "quanto mais internacional for uma instituição ou uma carreira, melhor”. Em seu ponto de vista, a justificação está na importância da internacionalização para a consolidação do reconhecimento individual e coletivo, conferindo vantagens na avaliação da "qualidade" e dos níveis de "excelência". A quase totalidade dos entrevistados frisa estruturalmente a relevância da internacionalização para o aumento da disposição crítica e avaliativa do trabalho realizado porque permite que o trabalho científico seja avaliado tendo em conta os padrões de investigação da área científica respetiva fora de Portugal (Q19, directora de Centro de Investigação; artes e humanidades). Por isso, argumentam que quanto mais se conhecer e partilhar conhecimento, "mais enriquecemos e alargamos os nossos horizontes" (Q2, vice-reitora).

Assim, a internacionalização surge definida como algo que "abre horizontes e oportunidades, coloca desafios alavancadores, favorece a complementaridade de recursos [...]" (Q13, director de Centro de Investigação; ciências naturais), "perante a realidade actual que é global" (Q17, director de Centro de Investigação; ciências da saúde), e, por isso, a internacionalização significa estabelecer "ligações internacionais que facilitam o upgrade de conhecimentos e a visibilidade internacional" (Q20, director de Centro de Investigação; ciências naturais), porque a internacionalização define-se como um processo de "abrir a janela e deixar o ar

3 Essa entrevista foi realizada em outubro de 2010. 
entrar! Significa, contactar, partilhar e colaborar em programas académicos e de investigação com investigadores, professores, internacionais. Abrir portas a alunos internacionais" (Q2, vice-reitor).

No Quadro 3 observa-se a disposição dos diversos entrevistados, conforme os níveis de concordância e de discordância demonstrados em relação à frase e conforme a justificação dada para esse posicionamento.

$\mathrm{Na}$ maioria das expressões, a internacionalização surge sinalizada como um processo que se desenrola dos países menos centrais para os países centrais, sendo em grande parte excluídas as colaborações com países mais deficitários, em termos de desenvolvimento da ciência e tecnologia. Um dos inquiridos afirma que a internacionalização só vale a pena "desde que seja feita com parceiros de qualidade e não o contrário” (Q4, pró-reitor). Mais uma vez, regressamos à constatação da dificuldade em avaliar se a melhor estratégia de internacionalização está na imitação dos países com centros melhor posicionados nos rankings internacionais ou na concentração sobre países em que a ciência e investigação nacionais podem encontrar espaços de expansão porque "o normal é sermos um centro internacional, com pessoas internacionais e localizadas cá, obviamente com um foco português, mas cada vez mais somos Europa" (E9; ciências da engenharia e tecnologia).

Como se nota, a concordância reúne o maior número de respostas (dezoito), apesar de oito evidenciarem algumas resistências, normalmente associadas à necessidade de selecionar parceiros.

A definição de internacionalização veiculada pelos entrevistados gravita as vantagens desta para a avaliação da qualidade do trabalho por meio do escrutínio de comunidades científicas externas. Estas surgem, por seu turno, representadas como polos que favorecem a atribuição de prestígio às instituições e aos investigadores. Observa-se, no entanto, que essa definição assenta, basicamente, sob os eixos da mobilidade de recursos humanos e do estabelecimento de colaborações e parcerias.

A análise da informação obtida permite diferenciar os discursos dos vice-reitores e reitores dos discursos dos diretores de centro.

Os primeiros, com uma posição que se distingue por ser marcadamente política e em cujos discursos observa-se a reprodução do discurso politicamente esperado sobre a inevitabilidade da internacionalização e das suas vantagens, tendem a dar relevância à mobilidade, veiculada e legitimada como uma das atividades mais imperativas no ato de internacionalizar o ensino e a investigação. Um dos pró-reitores entrevistados afirma:

O estabelecimento de relações profissionais personalizadas é a base de qualquer outro tipo de cooperação. A existência de redes internacionais firmadas no terreno, capazes de oferecer apoio mútuo e de compensar eventuais fragilidades específicas. A aposta institucional forte em mecanismos e procedimentos capazes de promover e facilitar a internacionalização (gabinetes de tradução; Gabinetes de apoio à promoção de candidaturas a nível internacional, em especial europeu, constituído por pessoas com formação na área, por exemplo). (Q8, pró-reitor) 
Quadro 3 - Nível de concordância com a frase sobre a importância da internacionalização

\begin{tabular}{|c|c|c|}
\hline & $\begin{array}{l}\text { Identificação do } \\
\text { Questionário }\end{array}$ & Observações \\
\hline \multirow[t]{2}{*}{ Concordância } & $\begin{array}{c}\mathrm{Q} 2 \\
\mathrm{Q} 3 \\
\mathrm{Q} 7 \\
\mathrm{Q} 8 \\
\mathrm{Q} 10 \\
\mathrm{Q} 11 \\
\mathrm{Q} 13 \\
\mathrm{Q} 17 \\
\mathrm{Q} 20 \\
\mathrm{Q} 22\end{array}$ & $\begin{array}{l}\text { - Conhecer culturas e partilhar conhecimento; } \\
\text { - Experiência e conhecimento adquiridos; } \\
\text { - Reconhecimento e melhoria contínua; }\end{array}$ \\
\hline & $\begin{array}{l}\text { Q1 } \\
\text { Q4 } \\
\text { Q5 } \\
\text { Q9 } \\
\text { Q12 } \\
\text { Q19 } \\
\text { Q21 } \\
\text { Q23 }\end{array}$ & $\begin{array}{l}\text { - Afirmação demasiado taxativa; } \\
\text { - Desde que seja com parceiros de qualidade; } \\
\text { - Apenas se trouxer reforço da excelência; } \\
\text { - Especificidades nacionais; }\end{array}$ \\
\hline \multirow[t]{2}{*}{ Discordância } & $\begin{array}{r}\mathrm{Q} 14 \\
-\quad \mathrm{Q} 16 \\
\mathrm{Q} 18\end{array}$ & $\begin{array}{l}\text { - Há necessidades de contexto; } \\
\text { - Caso a afirmação seja tomada em absoluto; } \\
\text { - Deve ser adequado ao mercado alvo; }\end{array}$ \\
\hline & $\begin{array}{ll} & \text { Q6 } \\
+\quad \mathrm{Q} 15\end{array}$ & - A internacionalização não é objectivo em si. \\
\hline
\end{tabular}

Fonte: Inquéritos por questionário $(\mathrm{N}=23)$.

Elaboração das autoras.

Os segundos, ocupando uma posição institucionalmente mais constrangida entre o nível das políticas e dos programas e o nível da ação individual, tendem a demonstrar um discurso mais crítico em relação aos programas e processos de mobilidade. Em sua ótica, estes podem não contribuir para o enriquecimento de competências e reforço das redes de investigação, se apenas se tiver em vista o aumento do número de estudantes ou de investigadores em mobilidade, assim como o número das publicações e dos projetos em parceria, e não forem consideradas as condições em que tais processos realizam-se.

Por isso, seu discurso apresenta traços de uma reflexividade irónica acerca do esforço político em aumentar o número de investigadores em mobilidade, pois consideram que esses programas podem abrir portas à fuga de cérebros. $\mathrm{O}$ excerto seguinte sinaliza o exercício dessa reflexividade que se pauta pela crítica à falta de orientação política sobre as infraestruturas à investigação:

A FCT seria um misto de agência de viagens e agência de emprego e para cada jovem acabado de sair da universidade, de acordo com determinado, por exemplo média de licenciatura ou de mestrado, arranjava-lhe um emprego num sítio 
qualquer. E não teríamos laboratórios, não teríamos bibliotecas, não teríamos centros sei lá do quê, não teríamos centros de ciências sociais, porque toda essa gente [...] a finalidade da fundação seria esse misto, que faria isso com certeza muito bem porque há muita experiência de agências de viagens em Portugal, e provavelmente sairia mais barato. E se conseguisse negociar uma forma com a instituição que recebesse esses estudantes, uma forma de o nome de Portugal aparecer de alguma maneira associado às publicações, até mesmo o gráfico célebre das publicações que os senhores ministros da ciência e do ensino superior gostam de propagandear na assembleia, dizendo que têm subido de uma forma estrondosa as publicações em Portugal, continuaria na mesma. Ninguém saberia perguntar, o povo da rua não saberia perguntar, o meu engraxador de sapatos ou o meu barbeiro se aquilo foi feito em Portugal ou não. Nem interessaria nada a barbeiro nem ao engraxador de sapatos, nada. Havia mobilidade, afinal, havia esta maravilha da mobilidade. Tornada ela própria o objectivo em si. (E1, director de Centro; ciências da saúde)

Com efeito, os discursos dos directores de centro e de elementos das equipas reitorias entrevistados coincidem no que concerne à ideia de que a internacionalização é um processo cujos efeitos positivos dependem da definição de estratégias adequadas aos recursos disponíveis. $\mathrm{Na}$ ótica dos entrevistados, a internacionalização depende da informação necessária, da facilidade processual e da sustentabilidade financeira do projeto, condições que consideram não estar plenamente asseguradas a nível nacional:

Sobre a disponibilização de informação, as oportunidades de estudar, ensinar e investigar em Portugal poderiam ser divulgadas no estrangeiro, de forma a atrair participantes internacionais, podendo também ser divulgados às instituições de ensino e de investigação nacionais os estrangeiros interessados em colaborar com instituições nacionais. Sobre a facilidade processual, recomendaria que se estudasse os processos de candidatura e de admissão ou de contratação de estrangeiros, de forma a expedir processos menos práticos, assegurando uma facilidade processual adequada. Em termos de sustentabilidade financeira, recomendo a ponderação do esforço financeiro que a internacionalização envolve, e a consciencialização que pode ser difícil conseguir um bom nível de internacionalização se esta não for subsidiada. Por outro lado, as condições financeiras do país parecem não permitir a distribuição de subsídios. (Q1, vice-reitor)

A ênfase dada às condições para a promoção da internacionalização aparece correlacionada com a necessidade de reforço dos padrões de qualidade e da "cultura" móvel dos cientistas. Para entrevistados, uma das formas de promoção da internacionalização surge por meio do estímulo aos contatos entre instituições, investigadores e alunos: 
A mobilidade de alunos, corpo docente e investigadores é, sem dúvida, uma forma de enriquecer a vivência universitária e de promover o respeito recíproco, independentemente das diferenças sociais, culturais e financeiras que existam a nível individual ou colectivo. Aliás, um dos objectivos que está na base do Programa Erasmus é promover o conhecimento mútuo, como forma de contribuir para a paz entre as nações. A internacionalização deve ser estimulada por todas as formas possíveis: tirando o máximo partido dos programas existentes; associando alunos a projectos internacionais que lhes proporcionem, quanto mais não seja, o contacto com investigadores estrangeiros que podem ter abordagens e soluções diferentes para problemas recorrentes da actividade de investigação; estimulando doutoramentos em co-tutela com universidades estrangeiras do maior número possível de países; procurando estabelecer programas de cooperação com universidades de renome internacional, cujo reconhecimento da nossa capacidade e qualidade servirá de referência internacional. (Q7, reitor)

A maioria dos entrevistados, tanto em cargos de direcção das universidades como dos centros de investigação e em todas as áreas científicas incluídas, considera ser necessário adequar o conceito de internacionalização às diferentes áreas científicas, às suas dinâmicas e processos de produção e disseminação do conhecimento. Fica vincada a ideia de que as diferentes áreas possuem diferentes modos de definir e de operacionalizar a internacionalização e, por isso, "devem ser respeitadas as suas [das ciências sociais] legítimas especificidade de investigação" (Q8, pró-reitor), pois:

No domínio das Humanidades, por exemplo, as publicações em coautoria são pouco frequentes, dado que a investigação tem uma componente de subjectividade muito forte, ao contrário do que acontece nas ciências, ditas duras, que se baseiam em dados quantificáveis e reprodutíveis. Isso não quer dizer que a internacionalização nessas áreas seja menos importante, apenas é mais difícil de quantificar, como é próprio desse domínio científico. (Q7, reitor)

De qualquer forma, embora com menor expressão, existe outra postura que se apresenta como mais "igualitária", argumentando em favor do uso do mesmo tipo de metodologia e de indicadores. Aponta como justificação a necessidade de uniformizar a avaliação entre áreas científicas, para que, dessa forma, possam ser comparáveis entre si, tendo em conta a dificuldade de ajustamento de avaliações distintas. Tendem a considerar que a "investigação é transversal a todas as áreas" (Q20, director de Centro de Investigação; ciências naturais).

Observa-se, assim, a complexidade na definição dos critérios de internacionalização da investigação nas diferentes áreas do conhecimento, designadamente se atendermos à própria definição do objecto nas ciências sociais, movidas por graus elevados de incerteza nos vários contextos socioculturais e históricos.

No quadro que apresentamos a seguir está descrita a informação sobre os níveis de concordância com a frase "Em Portugal, a avaliação do nível de 
Quadro 4 - Nível de concordância sobre o uso da internacionalização como critério de avaliação

\begin{tabular}{|c|c|c|c|}
\hline \multicolumn{4}{|c|}{$\begin{array}{l}\text { Identificação do } \\
\text { Questionário }\end{array}$} \\
\hline \multirow[b]{2}{*}{ Concordância } & + & $\begin{array}{l}\mathrm{Q} 1 \\
\mathrm{Q} 4 \\
\mathrm{Q} 20\end{array}$ & $\begin{array}{l}\text { - Conhecimento como transversal a } \\
\text { todas as áreas científicas; }\end{array}$ \\
\hline & - & $\begin{array}{l}\text { Q5 } \\
\text { Q7 } \\
\text { Q10 } \\
\text { Q12 } \\
\text { Q14 }\end{array}$ & $\begin{array}{l}\text { - Deve-se atender às especificidades e ao } \\
\text { desenvolvimento da área em si mesma; } \\
\text { - Pontuações adaptadas; }\end{array}$ \\
\hline \multirow[b]{2}{*}{ Discordância } & - & $\begin{array}{l}\mathrm{Q} 2 \\
\mathrm{Q} 3 \\
\mathrm{Q} 6 \\
\mathrm{Q} 8 \\
\mathrm{Q} 11\end{array}$ & $\begin{array}{l}\text { - Discordância, embora se deva tender para } \\
\text { uma uniformização de critérios; }\end{array}$ \\
\hline & + & $\begin{array}{l}\text { Q8 } \\
\text { Q9 } 13 \\
\text { Q13 } \\
\text { Q11 } \\
\text { Q16 } \\
\text { Q17 } \\
\text { Q11 } \\
\text { Q19 } \\
\text { Q21 } \\
\text { Q22 } \\
\text { Q223 }\end{array}$ & $\begin{array}{l}\text { - Devem ser respeitas as especificidades disciplinares } \\
\text { e desenvolvimento das áreas científicas. }\end{array}$ \\
\hline
\end{tabular}

Fonte: Inquéritos por questionário $(\mathrm{N}=23)$.

Elaboração das autoras.

internacionalização tem vindo a ser realizada usando o mesmo tipo de metodologia, em todas as áreas científicas”, assim como as justificações dadas pelos entrevistados. Observa-se, então, que aparentemente a posição maioritária está do lado da recusa de critérios uniformes (dezesseis), embora seja percetível a formação de uma vincada dualidade marcada por um número significativo de respostas que defendem a uniformização de critérios, sustentada pela ideia de que a ciência, para ser considerada como tal, deve produzir indicadores idênticos. No domínio da internacionalização fica explicita a dificuldade das ciências sociais e humanas em posicionar-se no exterior com temáticas originais, objeto de debate em contexto internacional, e, ao mesmo tempo, poder contribuir para o desenvolvimento local, regional e nacional de um país.

Um traço muito importante a ser destacado da análise dos dados materiliza-se na ausência de contributos específicos sobre as formas mais concretas de operacionalizar a medição da internacionalização, mesmo que esta fique definível como necessária e importante, quase imperativa, embora necessariamente ajustada aos objetivos e planos de desenvolvimento das instituições e, por isso, não homogénea, 
nem replicável, que " deve ser subordinada aos objectivos estratégicos da instituição. Pode-se fazer internacionalização que seja completamente irrelevante ou até prejudicial para o futuro da instituição. Não faltam exemplos" (Q6, vice-reitor).

A internacionalização é marcadamente explicada com recurso às vantagens da mobilidade de investigadores, permitindo:

nos colocarmos no mapa dos eventos científicos a nível europeu, ou seja de nos tornarmos mais visíveis. Por outro lado, criar com isso oportunidades de pesquisa e de interconhecimento. De pesquisa, de haver novas oportunidades de pesquisa, de financiamento, de participação em projectos e também de interconhecimento. Basicamente, é isso e também permitir aos investigadores mais jovens terem depois uma internacionalização aí. Porque uma coisa que se verifica é que, quando esses eventos acontecem em Portugal, há muitas comunicações de portugueses, até por razões logísticas, práticas, não é? Isso é um bom objectivo. (E7, diretor de Centro; ciências sociais)

\section{CONCLUSÃO}

A investigação e a educação superior estão agora a sobreviver em ambientes altamente seletivos, geridos pelas lógicas do sistema-mundo (Wallerstein, 1994, 2003) da ciência. A internacionalização representa, segundo alguns dos entrevistados, uma "peça-chave no ensino superior e na investigação em Portugal" que permite "o estabelecimento de laços entre instituições de países diferentes", mas sua operacionalização está ainda por discutir e debater tanto no nível nacional como institucional.

Os quadros teóricos apresentados que veiculam diversas formas de entendimento e de mensuração da internacionalização são unânimes na forma como argumentam a necessidade de a internacionalização solicitar um dimensionamento estratégico das universidades e dos centros de investigação, concertado com suas metas e missões. Tal como acontece com outras tendências manageriais no domínio da ciência e do ensino superior, a internacionalização surge frequentemente conotada com o nível da ação individual, isto é, como um eixo necessário ao desenvolvimento da carreira do investigador.

A reflexão propiciada por este texto permite evidenciar a relevância do nível institucional (das lideranças dos centros e das universidades na promoção de condições para a internacionalização e na definição dos tipos e graus de internacionalização apropriados), assim como das políticas e dos programas nacionais e seu ajuste a processos mais globais. Apenas como exemplo, destaquemos a gestão e a promoção concreta das colaborações internacionais, o trabalho sobre os mecanismos legais ajustados à mobilidade e à gestão da propriedade intelectual, assim como a gestão de mecanismos direccionados à redução dos tempos de produção de resultados de investigação e o apoio à disseminação científica. 


\section{REFERÊNCIAS}

Alatas, S. F. Academic dependency and the global division of labour in the social sciences. Current Sociology, Londres: Sage Publications, v. 51, n. 6, p. 599-613, 2005.

Albino, S. As políticas europeias de investigação e a internacionalização da Universidade de Lisboa. 2008. Tese (Mestrado em Políticas Europeias) - Universidade de Lisboa, Faculdade de Letras, Lisboa, 2008.

Amaral, A. et al. Processos de internacionalização e o ensino superior português. In: Teixeira, P. (Ed.). A Universidade do Porto e a internacionalização. Porto: Universidade do Porto, 2013.

Antelo, A. Internationalization of research. Journal of International Education and Leadership, [s.1.:s.n.], v. 2, n. 1, p. 1-6, 2012. Disponível em: <http://www.jielusa.org/ wp-content/uploads/2012/01/Internationalization-of-Research-Antelo.pdf>. Acesso em: 12 ago. 2012.

Araújo, E.; Silva, S. A última fronteira: EUA - contributos para a compreensão do papel da mobilidade nas carreiras de investigação. Madrid: Ricyt, 2010. Disponível em: <http://hdl.handle.net/1822/11495>. Acesso em: 21 mar. 2012.

Bourdieu, P. L'Homo academicus. Paris: La Haye, 1984.

Castells, M. A era de informação: economia sociedade e cultura. A sociedade em rede. São Paulo: Paz e Terra, 1999. v. I.

Fortuna, C. A internacionalização da sociologia: notas sobre a globalização e a disciplina sociológica. In: Torres, A.; Baptista, L. (Orgs.) Sociedades contemporâneas: reflexividade e acção. Porto: Afrontamento, 2008. p. 83-94.

Green, M. Measuring internationalization at research universities. Washington, DC; American Council on Education, 2005. Disponível em: <http://www.acenet.edu/ bookstore/pdf/2005FordResearch.pdf>. Acesso em: 12 ago. 2012.

Hakala, J. Internationalisation of science. Views of the scientific elite in Finland. Science Studies, Finlândia: Finnish Society for Science and Technology Studies, n. 1, p. 52-74, 1998.

Jons, H. Transnational mobility and the spaces of knowledge production: a comparison of global patterns, motivations and collaborations in different academic fields. Social Geography, Alemanha: Copernicus Publications, v. 2, n. 2, p. 97-114, 2007.

Knight, J.; Wit, H. Strategies for internationalisation of higher education: historical and conceptual perpectives. In: WIT, H.(Ed.). Strategies for internationalisation of higher education - a comparative study of Australia, Canada, Europe and the United States of America. Amsterdam: European Association for International Education, 1995.

Internationalisation of higher education. In: Wit, H. (Ed.). Quality and internationalisation in higher education. Amsterdam: Organization for Economic Cooperation and Development, 1999. p. 225-240. 
Internationalization remodeled: definition, approaches, and rationales. Journal of Studies in International Education, Londres: Sage Publications, v. 8, n. 1, p. 5-31, 2004.

Internationalization of higher education: new directions, new challenges. The 2005 IAU global survey report. Paris: International Association of Universities, 2006. Miura, I. K. O processo de internacionalizaçao da Universidade de São Paulo: um estudo de três áreas do conhecimento. 2006. Tese (Livre-Docência) - Faculdade de Economia, Administraçao e Contabilidade de Ribeirão Preto (FEA-RP), 2006.

Morosini, M. C. Estado do conhecimento sobre internacionalização da educação superior - Conceitos e prática. Educar, Curitiba: Setor de Educação da Universidade do Paraná, n. 28, p. 107-124, 2006.

Nunes, J. A.; Gonçalves, M.E.(Orgs.). Enteados de Galileu? A semiperiferia no sistema mundial da ciência. Porto: Afrontamento, 2001.

Pereira, T. S. Colaborações científicas internacionais e a diversidade dos sistemas de investigação: entre o global e o local. In: Nunes, J. A.; GonçAlves, M. E. (Orgs.). Enteados de Galileu? A semiperiferia no sistema mundial da ciência. Porto: Afrontamento, 2001.p. 143-170.

SERgE, S.; Wise, E. Internationalization of research and innovation - new policy developments. [S.1.]: European Commission; JRC; Gobierno de España, 2010. Disponível em: <http://iri.jrc.ec.europa.eu/concord-2010/papers/schwaag_serger_wise. pdf $>$. Acesso em: 12 ago. 2012.

SiegleR, J. M. B. O processo de internacionalização das instituições de ensino superior: um estudo de caso na Universidade Federal de Uberlândia. 2009. Dissertação (Mestrado em Administração de Organizações) - Faculdade de Economia, Administração e Contabilidade de Ribeirão Preto, Universidade de São Paulo, 2009.

Silva, S. (Re)pensar a internacionalização na investigação e no ensino superior. 2011. Dissertação (Mestrado em Sociologia) - Universidade do Minho, Braga, 2011.

SoDERQVIST, M. Internationalization and its management at higher education institutions: applying conceptual, content and discourse analysis. Helsinki: Helsinki School of Economics, 2002.

Stoer, N. Internacionalidade da ciência e nacionalidade dos cientistas, sociologia da ciência. Rio de Janeiro: Fundação Getúlio Vargas, 1975.

VeIgA, R. Internacionalização das instituiçôes de ensino superior em Portugal: proposta de metodologia para a construção de indicador do grau de internacionalização. 2012. Dissertação (Mestrado em Negócios Internacionais) - Escola Superior de Tecnologia e Gestão (ESTG) do Instituto Politécnico de Leiria, Leiria, 2012.

Wallerstein, I. O sistema mundial moderno. Porto: Edições Afrontamento, 1994. [V. II - O Mercantilismo e a consolidação da economia-mundo-europeia 1600-1750] Utopística ou as decisões históricas do século vinte e um. Petrópolis: Vozes, 2003. 


\section{SOBRE AS AUTORAS}

Emília Rodrigues Araújo é doutora em sociologia pela Universidade do Minho (Portugal). Professora da mesma instituição.

E-mail:era@ics.uminho.pt

Sílvia Silva é doutoranda em sociologia pela Universidade do Minho (Portugal).

E-mail: silviasilva.3942@gmail.com

Recebido em fevereiro de 2012

Aprovado em janeiro de 2013 